\title{
A mobile catenary power supply system for automotive vehicles
}

\author{
Tadeusz Maciołek ${ }^{1, *}$ \\ ${ }^{1}$ Warsaw University of Technology, Institute of Electric Power Engineering, Electric Traction Division, \\ ul. Koszykowa 75, 00-662, Warsaw, Poland
}

\begin{abstract}
Trolleybus type power supply using a two-pole overhead catenary system has been used for over one hundred years. However, energy demand in this type of road transport is the lowest. The main disadvantage of this type of transport is the lack of flexibility. Road electric vehicles equipped with batteries, which are now more and more often being put into service, allow for autonomous run on the roads without overhead contact wires. Therefore, it is possible to use them in a more flexible manner. The main problem is a limited range of autonomous run and long charge time of batteries. The paper presents a concept consisting in the application of an overhead catenary for supplying electric and hybrid vehicles (including automobiles) when a vehicle is in motion (mobile charging). Electric trucks are equipped with controlled current collectors allowing for connection with an overhead catenary during driving. Application of this solution to automobiles is rather impossible, which prevents them from being supplied directly from a catenary. The basis of the original concept presented in the paper is the creation of automobile convoys supplied via a truck equipped with current collectors. A description of the proposed system and an algorithm of its operation are presented in the paper. The discussed transport system has significant advantages in comparison to completely autonomous electric vehicles: increased range of driving with lower capacity of batteries on board and flexibility of use, longer life-time of batteries, lower energy consumption. The paper compares the proposed system with the currently used ones, which employ charging of automobiles during stops, but also underlines the advantages of the first solution.
\end{abstract}

\section{Current solutions for mobile charging of automobiles}

In Sweden, currently tests are being conducted for binary catenary supply of electric trucks equipped with current collectors. A 2-km section was launched in 2016. Further test sections are planned in the USA and Germany [1]. The basic difference between the trolleybus power supply system and the mentioned solution is higher speed (up to $90 \mathrm{~km} / \mathrm{h}$ ) and possibility of connecting pantographs during drive with the maximum speed. It is estimated that the maximum operational speed of such systems may be increased up to $140 \mathrm{~km} / \mathrm{h}$. In case of electric or hybrid automobiles with batteries, modern technical solutions for a catenary and smart current collectors would allow smooth drive at the demanded speed along sections with or without a catenary. It makes automobile driving flexible. The height of catenary suspension over a road (due to safety reasons) requires high mounting of current collectors, which are heavy and bulky. Therefore, vehicles should form a solid and stable construction. So, this solution may be used to supply busses and trucks rather than cars.

Application of mobile charging will reduce the need for stops required for charging of batteries, costs of exploitation and the number of batteries due to their lower energy capacity required (lower number of charging/discharging cycles and depth of discharging batteries, lower energy losses).

Other tested solutions include wireless inductive power supply of vehicles, including cars [2,3]. However, the main drawback of this type of power supply is high energy transfer loss $(>12 \%)$, due to additional energy transformation $\mathrm{DC} / \mathrm{AC}$ at high frequency in infrastructure and $\mathrm{AC} / \mathrm{DC}$ in vehicles [2,4]. Increased losses are also caused by atmospheric conditions and higher position tolerance of receiver coils in vehicles. For comparison - losses of energy transmission from a DC catenary to a vehicle are below $0.5 \%$ when the level of voltage in a catenary is above $600 \mathrm{~V}$ DC [5]. Due to the necessity of installing a greater number of high frequency converters, investment costs in power supply infrastructure will be a few times higher than in the case of an overhead catenary. Simultaneously, other studies are carried with the focus being put on solutions for road transport oriented towards reduction of energy consumption and increase of traffic safety. Successful tests of cooperative drive of individual cars, narrowly spaced, forming a convoy have been conducted $[6,7]$. Reduction of fuel used by cars in such a convoy is over a dozen percent. Equipment required for car control automation process allowing cars to drive at minimum spacing is currently being installed in serially manufactured cars. So, it is possible, using different available solutions and by modernizing them, to create a

\footnotetext{
* Corresponding author: tadeusz.maciolek@ee.pw.edu.pl
} 
new road transport system, which could reduce fuel consumption and the number of drivers, which constitutes $70 \%$ of exploitation costs of cars [7]. Reduction of these costs is essential for operation of cars.

\section{Convoy system with energy transmission between vehicles}

This paper proposes a new Mobile Catenary Power Supply Convoy Cars (MCPSCC) system, with its main concept presented in Fig. 1.

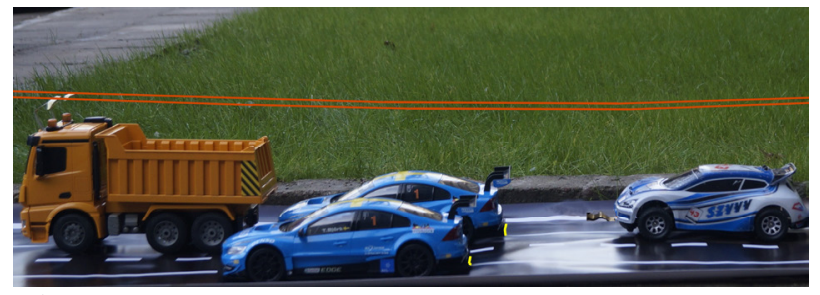

a.) Connecting a new vehicle at the end of convoy

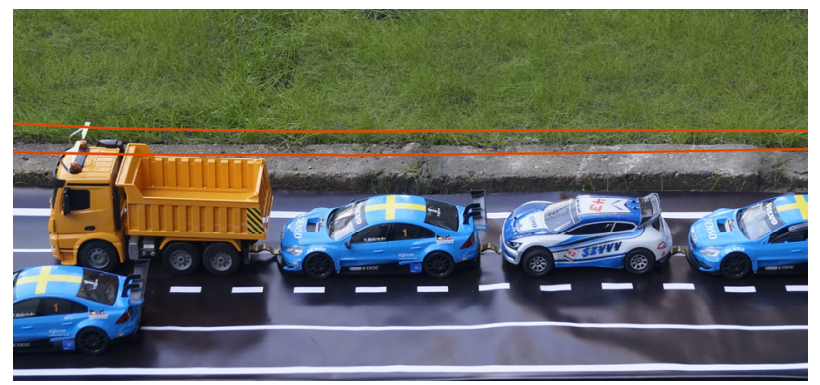

b.) driving in a convoy

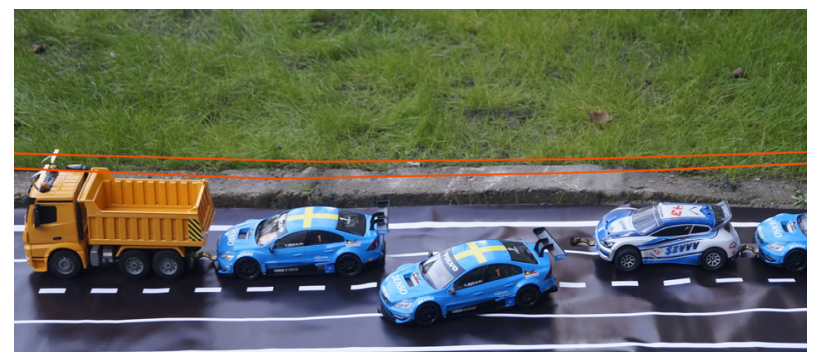

c.) disconnecting from a convoy

Fig.1. A convoy in different phases of operation.

In this system, cars are composed into a road train via DC electric disconnectable connectors [8]. Connecting and disconnecting of the cars forming a convoy is possible during driving with a maximum speed. Any car in a convoy may leave it at any point of road. The convoy is headed by a Pilot - a vehicle equipped with current collectors and power connector allowing energy transfer from a catenary to cars connected to the Pilot. The Pilot is a truck or a bus with a central unit controlling the whole convoy and cars as well data transmission between the Pilot and cars, and it sends information about availability of 'space' for another car to connect the convoy. All cars in a convoy must have unified connectors in front and at the back.
The proposed MCPSCC system has the following advantages in comparison with individual traffic of cars:

- lower energy consumption,

- increased driving range,

- longer lifecycle of batteries,

- higher safety,

- higher traffic capacity of a road lane,

- decreased fatigue of drivers,

- lower unitary costs of transport,

- lower environmental load,

with flexibility of individual car transport maintained.

However, some drawbacks are evident:

- the road must have at least one lane equipped with an overhead catenary,

- equipment of cars must be unified (automatic power connectors allowing connection/disconnection at maximum drive speed),

- due to close distances between cars $(<1 \mathrm{~m})$ an automatic operation of vehicles during connection to/disconnection from a convoy is a must.

- central control unit in the Pilot vehicle must be used,

- continuous wireless data transmission between cars in a convoy is required,

- continuous data wireless transmission between a central control unit in the Pilot vehicle with an external data transmission network is necessary to enable localization of a specific convoy for connection.

Road convoys are assembled dynamically and the algorithm of operation may be as follows. When entering the road with a catenary, the Pilot vehicle, equipped with a double pantograph, power connector and the main computer announces, by WWW network, readiness to supply vehicles on a specific section of a road. Drivers of other vehicles (including cars) receive information about position of the Pilot and may connect the convoy, if driving in the same direction. Vehicles connect the convoy at its end part. The process of connecting an individual vehicle to the convoy, driving in the convoy and disconnecting is to be organized automatically with superior control by the Pilot's CPU. Disconnecting of any vehicle from the convoy may be done at any point of the road. The procedure requires forming gaps between the vehicle disconnecting from the convoy and the adjacent vehicles. The vehicle leaving the convoy changes a road lane and other vehicles can connect to the convoy again. When the Pilot vehicle leaves the convoy, the convoy is dissolved. At roads with low density of traffic or when a truck, which could operate as a Pilot vehicle, is excluded from traffic, it is possible to introduce special vehicles dedicated to operate as Pilot vehicles. Settlement of fees for energy consumption is to be done remotely with the use of smart energy counters installed on board of vehicles prepared to run in convoys. 


\section{Comparison of energy consumption by cars driving individually and in a convoy}

Energy delivery to a DC supplied catenary from traction substations is associated with losses due to energy conversion and transmission, with ranges depending on the level of consumed voltage and power. The higher the voltage, the lower the losses (approx. 10\%). A similar level of losses may be observed at stationary points of fast charging of electric vehicles. So, the following analysis concerns energy consumption by vehicles only. For energy consumption to be reduced, it is required that a distance between vehicles in a convoy is below $1 \mathrm{~m}$. Tests in an aerodynamic tunnel have shown [3] that aerodynamic resistances to motion could be reduced by $50 \%$ in comparison to resistances of a car driving individually $\left(\mathrm{C}_{\mathrm{D}} / \mathrm{C}_{\mathrm{D} 0}\right.$-Fig. 2). Automobiles driving in a convoy with a very small distances imposed by electric couplings may also ensure significant decrease of consumed energy.

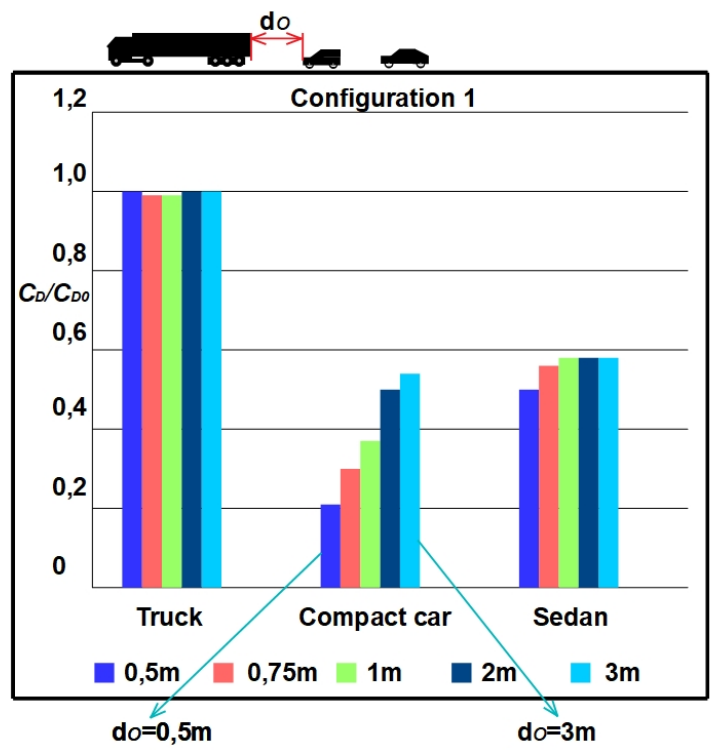

Fig.2. Dependence of aerodynamic resistance of a car driving in a convoy with a track compared with a car driving individually on a distance between driving cars. [3]

A comparison analysis for a car driving in a mix cycle, individual car and a car in a MCPSCC convoy is presented below.

A passenger car with typical parameters:

- mass $1,560 \mathrm{~kg}$,

- car's frontal area $\left[\mathrm{m}^{2]}\right.$,

- battery capacity of $36 \mathrm{kWh}$,

- mass of batteries and external connector - $200 \mathrm{~kg}$,

- efficiency of a drive system - $85.5 \%$,

- coefficient of aerodynamic resistance for a car:

- driving individually 0.35

- driving in a convoy 0.2 .

Battery capacity of a convoy car was only slightly reduced, but its mass remained the same.

A UDDS urban driving cycle and a HFWET motorway driving cycle were assumed [9]. As it was expected energy consumption during a urban duty cycle (UDDS) for both types of cars (driving individually and in a convoy) are practically the same $-1.52 \mathrm{kWh}$. In a motorway driving cycle (HFWET), a convoy car uses $21 \%$ less energy - only $2.3 \mathrm{kWh}$ than the second one $2.9 \mathrm{kWh}$ (Fig.4.). The savings result from lower aerodynamic resistances in a convoy. Forming a convoy of cars is required due to the operational principle of a system with a catenary power supply (MCPSCC), but a convoy of cars without catenary supply will have the same energy savings. However, when there are no catenary supply losses during frequent charging/discharging processes, it will still contribute to higher energy consumption. When catenary supply of a convoy is applied, the distance of driving under a catenary is limited by the length of catenary sections.

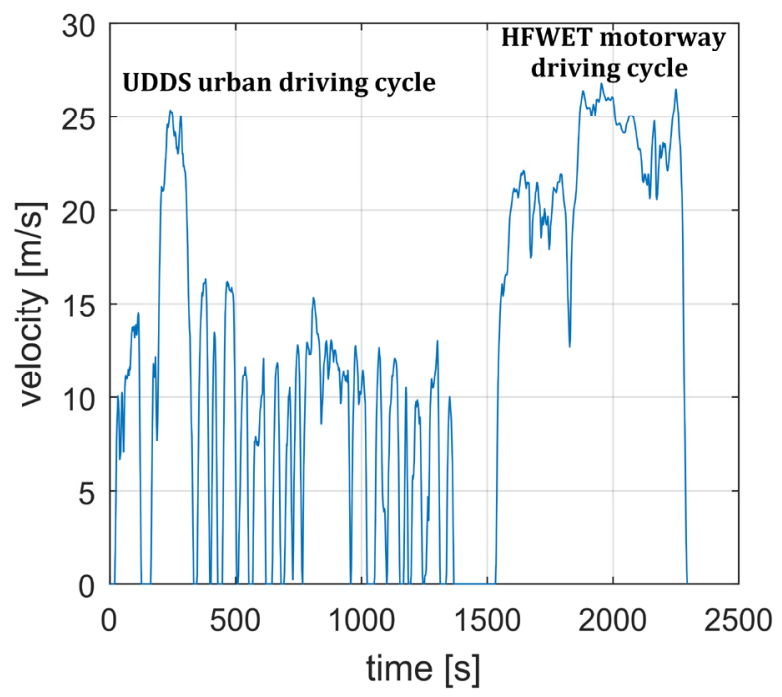

Fig.3. Speed profiles of a UDDS urban driving cycle and a HFWET motorway driving cycle used for the analysis of energy consumption by a vehicle.

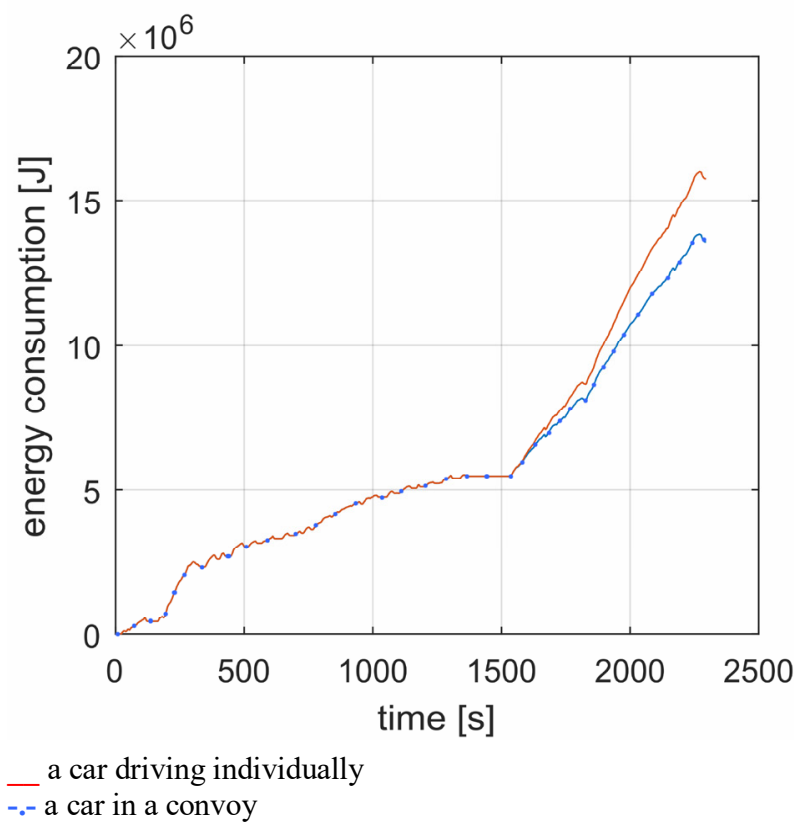

Fig.4. Energy consumption of a car driving individually and in a convoy. 
Unlimited availability of power for cars during driving in a convoy makes it possible to use energy consuming auxiliary loads as air-conditions. Usage of auxiliary loads will significantly reduce SoC of battery when autonomous (no-catenary) driving is applied.

\section{Comparison of mobile charging solutions}

Catenary power supply for mobile charging requires construction of power supply infrastructure along a road. A schematic drawing of such a system (MCPSCC) is shown in Fig. 5. Since in a catenary there is low DC voltage present (below $1000 \mathrm{~V}$ ), cars may be supplied directly from the catenary.

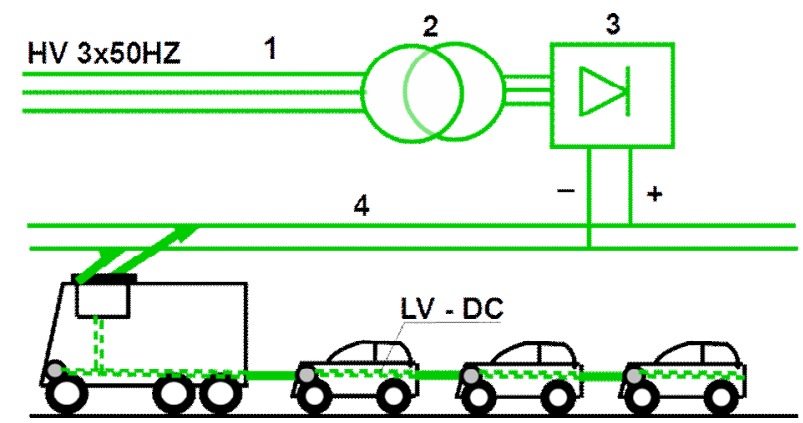

Fig. 5. A network power supply circuit for cars:

1- HV - high voltage power supply from a AC $50 \mathrm{~Hz} 3$ phase

2- transformer

3 - rectifier

4- low voltage (LV) DC power network

Wireless power supply of cars requires more complex infrastructure $[2,4,10]$ (Fig. 6), including $\mathrm{DC} / \mathrm{HF}$ energy conversion.

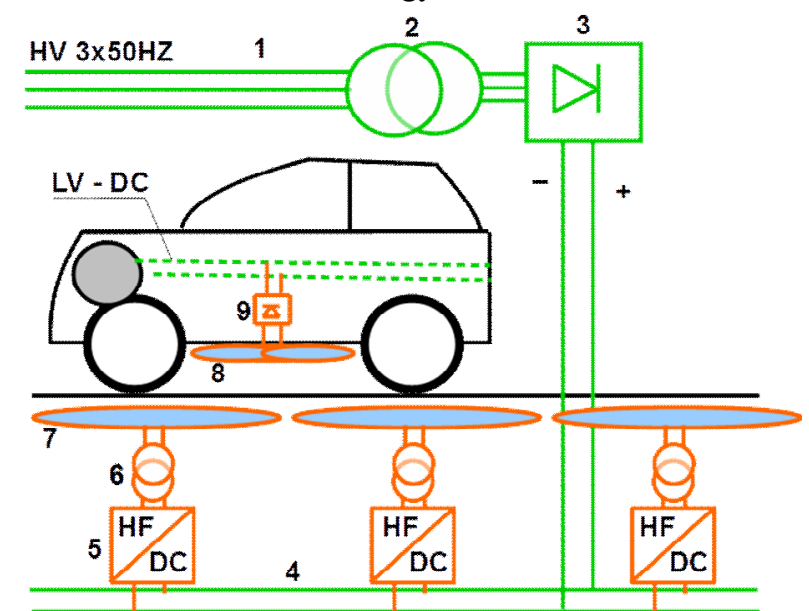

Fig.6. A scheme of a wireless power supply circuit of cars

1- HV - high voltage power supply from a AC $50 \mathrm{~Hz} 3$ phase

2- transformer

3 - rectifier

4- low voltage (LV) DC power network

5- HF (high frequency) generator

6- HF transformer

7- transmitter coil

8 - receiver coil

9 - rectifier in a car
Therefore, investment costs are much higher than in the case of network power supply infrastructure. Other advantages of catenary power supply over wireless power supply are as follows:

- higher reliability,

- lower transmission losses (only $<0.5 \%$ of losses at a contact point : pantograph-catenary at $750 \mathrm{~V} \mathrm{DC}$ in comparison to $10 \%$ or more during inductive energy transfer),

- lower EMF emission,

- higher power of transfer (possible $750 \mathrm{~kW}$ of power delivered to a convoy of vehicles via 2 pantographs supplied by a $750 \mathrm{~V} \mathrm{DC}$ catenary).

Such power allows for supply of a convoy composed of 7 trucks, each with mass of $24 \mathrm{Mg}$ or a Pilot and 40 electric cars driving at a speed of $100 \mathrm{~km} / \mathrm{h}$.

When speed exceeds $100 \mathrm{~km} / \mathrm{h}$, power demand increases significantly (aerodynamic resistances are proportional to square of speed). Maximizing the number of cars in a convoy will result in all available power being used for driving and opportunity of charging of batteries will be reduced. When the number of cars is smaller, it is possible to charge their batteries as well. Cost of power supply infrastructure depends on the length of catenary sections and power demand. Increase of a length of sections supplied by one traction substation will increase losses of transmission due to low catenary voltage.

Methods of analysis and design applied in urban transport power supply systems [5] could be used to design the proposed power supply system. Since cars are equipped with batteries, it will be possible to drive on sections of a road without a catenary, where needed. In the most extreme cases only $30-40 \%$ of the length of a road for convoy driving must be equipped with a catenary. So, development of this system may be done step-by-step by increasing the length of catenary sections and the number of substations according to the demand for power dependent on the increasing traffic density.

\section{Conclusion}

The presented analysis has shown that catenary supplied cars in convoys used in a HFWET road cycle require $20 \%$ less energy for driving than individually driving autonomous electric cars. The use of wireless power supply will increase energy demand by another $10 \%$ comparing with the catenary supplied cars in convoys.

It was assumed that maximum speed of cars in a convoy is $100 \mathrm{~km} / \mathrm{h}$; however increase of speed to 120 $\mathrm{km} / \mathrm{h}$ is assumed to be possible when automatic Pilot vehicles with pantographs driving at such a speed will be used.

Increase of speed will increase traffic capacity of the MCPSCC system.

Main advantages of the proposed MCPSCC system are as follows:

- increased range of electric car application with maintenance of flexibility and autonomy, 
- reduction of energy capacity of batteries on-board of cars and a discharge level as well as the number of required cycles of charging/discharging, which increases lifetime of batteries,

- elimination of breaks required for charging of batteries and opportunity for mobile charging,

- reduction of energy consumption due to lower number of charging/discharging cycles and lower energy demand by a car driving in a convoy (in comparison to individual drive),

opportunity to develop the MCPSCC system step-by step according to traffic power demand (at the beginning only $30-40 \%$ of the road is to be equipped with a catenary). The presented system requires construction of a power supply catenary along the highways.

It also necessitates that the cars be equipped with electromechanical couplings executed as per a uniform standard. Currently, traffic of vehicles grouped in such long convoys is not permitted; therefore, changes in traffic law are required as well.

\section{References}

1. SIMENS Corporation, eHighway - Solutions for electrified road freight transport, https://www.siemens.com/press/ehighway

2. O.C. Onar, System Design and Experiment, in Wireless Power Transfer Systems, IEEE Transportation Electrification Conference and Expo, : Part 2 (2013)

3. P. Schito, F. Braghin,. Numerical and Experimental Investigation on Vehicles in Platoon, SAE Int. $J$.
Commer. Veh., 63-71, (2012), doi:10.4271/2012-010175

4. S. Judek, K. Karwowski, Contactless electrical energy transfer system via magnetically coupled air coils, (Gdańsk : Wydaw. PG, 2013. - ISBN 978-837348-501-3)

5. A. Szeląg, Z. Drążek, T. Maciołek, Power supply systems of urban electric traction (IN-W „Spatium”, Radom, 2017) [in Polish: Elektroenergetyka miejskiej trakcji elektrycznej]

6. K-Y. Liang, Fuel Efficient Heavy-Duty Vehicle Platoon Formation, (PhD thesis, KTH Stockholm, Sweden, 2016)

7. N. Lyamin, Q. Deng, A. Vinel, Study of the Platooning Fuel Efficiency under ETSI ITS-G5 Communications, IEEE 19th International Conference on Intelligent Transportation Systems (ITSC), (2016) doi.org/10.1109/ITSC.2016.7795608

8. T. Maciołek, A. Szeląg, Power supply of electric cars, Polish patent application PL-418194, (2016) [in Polish: System zasilania samochodów elektrycznych]

9. Urban Dynamometer Driving Schedule "LA4" The UN/ECE Regulation 53 refers to the EPA UDDS, Highway Fuel Economy Driving Schedule (HWFET) www.epa.gov/vehicle-and-fuelemissions-testing/dynamometer-drive-schedules

10. T-E. Stamati, P. Bauer, On-road charging of Electric Vehicles, Proceedings of IEEE Transportation Electrification Conference and Expo, 1-8 (2013) 